\section{Variability in letter-matching asymmetry}

\author{
DAVID B. BOLES \\ University of Texas, Arlington, Texas 76019
}

Pairs of letters presented simultaneously and matched for identity have been reported to show opposite visual field superiorities, depending on whether the match must be made along a physical or along a name dimension (Davis \& Schmit, 1973; Geffen, Bradshaw, \& Nettleton, 1972; Umilta, Sava, \& Salmaso, 1980). Thus, physically identical pairs (e.g., AA) are reported to show significant left visual field (LVF) advantage in response time, while nominally identical pairs (e.g., Aa) reportedly show right visual field (RVF) advantage. Under current interpretations of VF asymmetry, these differences are taken to reflect the operation of right-hemisphere visuospatial and left-hemisphere verbal processes, respectively.

The first seven of the present experiments in lettermatching were conducted several years ago while the author was affiliated with the University of Oregon. They have not been reported prior to this time because it had appeared that interest in the paradigm, at least from a hemispheric standpoint, had declined following a flurry of research in the years 19701977 (Cohen, 1972, 1973; Davis \& Schmit, 1973; Gazzaniga, 1970; Geffen et al., 1972; Green, 1977; Hellige, 1975, 1976; Lefton \& Haber, 1974; Levy, 1974; Wilkins \& Stewart, 1974; Green \& Well, Note 1). However, recently there has been a resurgence of interest (Hellige, Cox, \& Litvac, 1979; Ledlow, Swanson, \& Kinsbourne, 1978; Segalowicz \& Stewart, 1979; Simion, Bagnara, Bisiacchi, Roncato, \& Umilta, 1980; Umilta et al., 1980), and so the present experiments are contributed in the interests of a more balanced viewpoint in the literature.

\section{METHOD}

In general, letter pairs were presented on a CRT controlled by an on-line PDP-15 computer, which ordered the trial sequences and recorded responses. Members of letter pairs were typically presented along a horizontal line following the procedure of two previous research groups (Geffen et al., 1972; Segalowicz \& Stewart, 1979), who, it must be emphasized, produced the pattern of visual field effects mentioned above. Pairs were always preceded by a fixation point in central vision, and subjects were instructed to keep their eyes fixated on this point.

This research was supported by National Institute of General Medical Science Grant 5 TO 1 GMO 2165. The author wishes to thank Steven Keele and Michael Posner for their intellectual and moral support during this project. Reprint requests should be addressed to David B. Boles, Department of Psychology, Box 19528, University of Texas at Arlington, Arlington, Texas 76019.
The following, in brief form, are the methods used in each of the eight experiments:

In Experiment 1, 12 subjects matched letter pairs for physical or name identity in mixed blocks. The letter set was A, E, M, and $R$ in upper- and lowercase, with pair members presented simultaneously for $150 \mathrm{msec}$ in one VF or the other. There were 384 trials given (following 192 practice trials): half were same matches (composed of half physical matches and half name matches), and half were different matches. Response was on a two-key board, with one key in front of the other relative to the subject; one key was designated the "same" key and the other the "different" key, with the designation balanced over subjects. The subject pressed the key with both hands, using the two thumbs for the near key and the two index fingers for the far key. In this experiment and in all others, when relevant, the subjects were instructed to respond "same" to both physically and nominally identical pairs.

Experiment 2 was identical to Experiment 1, except that, to increase outline integrity, the letters were triple-plotted with slight horizontal and vertical displacement of constituent dots. "Different" pairs were constructed to subjectively maximize their dissimilarity. The letters used were $\mathrm{D}, \mathrm{H}, \mathrm{L}$, and $\mathrm{R}$. The working hypothesis was that making the task easier than the relatively difficult one in Experiment 1 might better replicate previously published asymmetries.

Experiment 3 was identical to Experiment 2, except that a full session of 576 practice trials was given the preceding day, an additional 256 practice trials were given the day of the experiment, and 13 subjects participated. The working hypothesis again was that making the task easier might produce more "typical" asymmetry.

Experiment 4 was identical to Experiment 1, except that the response was with one hand only. There were 128 practice trials with one hand, followed by 256 experimental trials. This procedure was repeated with the other hand. The order of hands was balanced over subjects. The working hypothesis was that Experiments 1-3 may have failed to produce "typical" asymmetry because of possible VF by Hand interactions obscured by the bimanual response mode used in those experiments.

Experiment 5 was identical to Experiment 1, except that no physical matches were used and 64 practice trials were followed by 192 experimental trials in which the response was either bimanual (in half the subjects) or unimanual with the right hand (in the other half), with this procedure repeated for the other response mode. The working hypothesis was that bimanual vs. unimanual responses might account for some of the variance in name-match asymmetry.

In Experiment 6, 16 subjects matched letter pairs for physical identity in blocks in which simultaneous and successive presentations were mixed. Simultaneous presentations used the letters A, $\mathbf{E}, \mathbf{M}$, and $\mathbf{R}$ in upper- and lowercase, with pairs presented for $90 \mathrm{msec}$ in one visual field or the other. Successive presentations used the letters $\mathrm{A}, \mathrm{E}, \mathrm{F}, \mathrm{H}, \mathrm{O}$, and $\mathrm{U}$ (in right-angle block form), with the initial letter presented at fixation for $50 \mathrm{msec}$, followed by a fixation point for $1,000 \mathrm{msec}$ and then the second letter in one visual field for $100 \mathrm{msec}$. Responses were made on a single key in a go/no-go paradigm: "go" for same matches, "no go" for different matches. Thirty-four practice trials using one hand preceded 136 experimental trials using the same hand (72 successive and 64 simultaneous, with half of each being same matches); the procedure was repeated with the other hand, and hand order was balanced across subjects. The working hypothesis was that there would be an interaction between the simultaneous vs. successive procedures: the former was similar to Experiments 1-4 and, it was hoped, would result in a similar RVF advantage; the latter was similar to an experiment by Bagnara, Boles, Simion, and Umilta (Note 2) in which a slight LVF advantage was obtained.

Experiment 7 was identical to Experiment 6, except that 14 
subjects were used, and the practice trials were succeeded by 272 experimental trials (144 successive and 128 simultaneous). This was essentially a replication of Experiment 6.

Experiment 8 was identical to Experiment 1, except that one member of the pair was presented at central fixation, and the other member in one VF or the other. The working hypothesis was that the bilateral nature of this task (i.e., the central member overlaps the visual midline) might produce "typical" asymmetry (Boles, 1979; McKeever \& Huling, 1971; Olson, 1973).

\section{RESULTS}

Reaction times (RTs) and errors were analyzed in each of the eight experiments in each of three conditions: (1) physically identical pairs, (2) nominally identical pairs, and (3) different pairs. In all cases, parametric tests were used to assess VF asymmetry. The results for RTs are given in Table 1 and those for errors in Table 2.

\section{DISCUSSION}

An initial question to consider in examining these results is whether variability in the visual field difference scores can be systematically attributed to variations in design and procedure. Assuming the
RT data to be of primary importance, physical match scores seem to bear the greatest relationship to the use of choice vs. go/no-go responses, but this relationship is not strong. Although both go/no-go experiments ( 6 and 7 ) produced essentially zero visual field differences, so did two of the choice experiments (2 and 8 ). Similarly, while the strongest relationship to name-match asymmetry is to the use of singly vs. multiply plotted letters and to the associated factor of similarity within "different" pairs, both types of presentation produced positive VF differences in certain instances (compare Experiments 2 and 3 with Experiments 4 and 8). Finally, the different match scores seem to be most closely related to the amount of practice preceding experimental trials, yet relatively large (although generally nonsignificant) scores were obtained in both lowpractice (Experiment 5) and high-practice experiments (Experiment 2). It would therefore appear that variations in VF difference scores cannot be systematically attributed to procedural variations over experiments.

The present results can be characterized by looking to overall effects found within each type of match.

Table 1

Mean RT in Each Condition of the Eight Experiments

\begin{tabular}{|c|c|c|c|c|c|c|c|c|c|c|}
\hline \multirow{3}{*}{$\begin{array}{c}\text { Experi- } \\
\text { ment }\end{array}$} & \multirow[b]{3}{*}{$\mathrm{n}$} & \multicolumn{6}{|c|}{ Same Matches } & & & \\
\hline & & \multicolumn{3}{|c|}{ Physical Matches } & \multicolumn{3}{|c|}{ Name Matches } & \multicolumn{3}{|c|}{ Different Matches } \\
\hline & & LVF & RVF & Difference & LVF & RVF & Difference & LVF & RVF & Difference \\
\hline 1 & 12 & 583 & 556 & $+27 \dagger$ & 672 & 683 & -11 & 683 & 681 & +2 \\
\hline 2 & 12 & 537 & 536 & +1 & 628 & 618 & +10 & 643 & 633 & +10 \\
\hline 3 & 13 & 517 & 501 & $+16 * *$ & 613 & 600 & +13 & 614 & 611 & +3 \\
\hline $4^{1,2}$ & 12 & 635 & 615 & $+20^{*}$ & 709 & 703 & +6 & 714 & 698 & $+16 \dagger \dagger$ \\
\hline $5^{3}$ & 12 & & & & 682 & 699 & -17 & 736 & 723 & +13 \\
\hline $6^{1,4}$ & 12 & 479 & 479 & 0 & & & & & & \\
\hline $7^{1,4}$ & 14 & 443 & 442 & +1 & & & & & & \\
\hline 8 & 14 & 617 & 622 & -5 & 693 & 688 & +5 & 689 & 690 & -1 \\
\hline
\end{tabular}

Note-Superscripts indicate the following selected nonsignificant interactions: (1) VF by Hand, (2) VF by Type of Match (physical vs. name) by Hand, (3) VF by Response Mode (bimanual vs. unimanual), (4) VF by Presentation Mode (simultaneous vs. successive). ${ }^{*} p<.05$. * * $p<.025$. tp $<.01$. ttp $<.001$.

Table 2

Mean Percent Errors in Each Condition of the Eight Experiments

\begin{tabular}{|c|c|c|c|c|c|c|c|c|c|c|}
\hline \multirow{3}{*}{$\begin{array}{c}\text { Experi- } \\
\text { ment }\end{array}$} & \multirow[b]{3}{*}{$\mathbf{n}$} & \multicolumn{6}{|c|}{ Same Matches } & & & \\
\hline & & \multicolumn{3}{|c|}{ Physical Matches } & \multicolumn{3}{|c|}{ Name Matches } & \multicolumn{3}{|c|}{ Different Matches } \\
\hline & & LVF & RVF & Difference & LVF & RVF & Difference & LVF & RVF & Difference \\
\hline 1 & 12 & 7.9 & 4.8 & $+3.1 * *$ & 23.3 & 23.5 & -.2 & 14.1 & 18.6 & $-4.5^{*}$ \\
\hline 2 & 12 & 6.3 & 6.5 & -.2 & 24.8 & 21.3 & +3.5 & 16.3 & 14.6 & +1.7 \\
\hline 3 & 13 & 5.2 & 4.8 & +.4 & 18.3 & 17.1 & +1.2 & 9.9 & 10.7 & -.8 \\
\hline 4 & 12 & 12.4 & 7.4 & $+5.0^{*}$ & 30.6 & 28.1 & +2.5 & 20.6 & 15.5 & $+5.1^{*}$ \\
\hline 5 & 12 & & & & 22.3 & 23.1 & -.8 & 17.2 & 17.0 & +.2 \\
\hline 6 & 12 & 10.2 & 5.0 & $+5.2 \dagger$ & & & & & & \\
\hline 7 & 14 & 2.7 & 2.0 & +.7 & & & & & & \\
\hline 8 & 14 & 6.2 & 6.1 & +.1 & 15.2 & 15.8 & -.6 & 8.6 & 10.5 & -1.9 \\
\hline
\end{tabular}

$* p<.05 . \quad * *<<.025 . \quad t_{p}<.001$. 
Physical matches produced significant asymmetry favoring the RVF in three of seven experiments, and the size of this asymmetry can be given as $7 \mathrm{msec}$, using a weighted-means estimate over all experiments. (This effect also appeared in the error data.) Name matches failed to produce significant asymmetry in any single experiment, and the weighted-means estimate gives $1 \mathrm{msec}$ as an estimate of the RVF advantage, over the entire series. (This lack of an effect is also apparent in errors.) Finally, there was some indication of a RVF superiority for different matches in the RT data, with this trend appearing in five of six experiments and being significant in one; the weighted-means procedure yields $5 \mathrm{msec}$ as the size of this effect. However, in this case there were conflicting results in the error data, so perhaps this trend should not be considered meaningful.

These results are at variance with the predominant view in published letter-matching studies. However, what has not been recognized is that the literature is by no means in complete agreement on the direction of asymmetry in letter matching. Thus, the "typical" LVF superiority was found (either significantly or by way of a trend) for physical match RTs in six studies (Cohen, 1972; Davis \& Schmit, 1973; Geffen et al., 1972; Lefton \& Haber, 1974; Segalowicz \& Stewart, 1979; Umilta et al., 1980), and possibly a seventh if the short ISI condition of Wilkins and Stewart (1974) is considered; but the RVF was superior in four others (Cohen, 1973; Egeth \& Epstein, 1972; Ledlow et al., 1978; Simion et al., 1980). Similarly, at least a slight RVF effect was found for name matches in 10 studies (Cohen, 1972; Davis \& Schmit, 1973; Gazzaniga, 1970; Geffen et al., 1972; Hellige et al., 1979; Ledlow et al., 1978; Levy, 1974; Segalowicz \& Stewart, 1979; Simion et al., 1980; Umilta et al., 1980); yet there was a LVF advantage in four (Hellige, 1975, 1976; Lefton \& Haber, 1974; Wilkins \& Stewart, 1974). Different matches are even more equivocal: RVF effects were found in six (Cohen, 1972; Davis \& Schmit, 1973; Geffen et al., 1972; Hellige, 1976; Simion et al., 1980; Umilta et al., 1980), but LVF effects were found in another five (Cohen, 1973; Egeth \& Epstein, 1972; Hellige, 1975; Hellige et al., 1979; Wilkins \& Stewart, 1974).

Including the present results in this review of the literature produces a view of letter-matching asymmetry as being highly variable. Unfortunately, the reasons for the discrepancies are no clearer to this researcher now than they were when the present experiments were conducted. One possible explanation can be immediately rejected: Vertical vs. horizontal placement of letter pairs bears no relationship to the asymmetry obtained (Davis \& Schmit, 1973; Egeth \& Epstein, 1972; Geffen et al., 1972). Thus, the suggestion that horizontal placement encourages reading tendencies (Cohen, 1972) that might produce an overall VF advantage in one direction is not sup- ported by the previous data. Nor can it account for the present results, since such a tendency should operate over all pairs, yet there was no suggestion of a RVF advantage for name matches to accompany that for physical matches. Indeed, the VF by Type of Match (physical vs. name) interaction was significant in Experiment $1(\mathrm{p}<.01)$.

A second possible explanation, that interactions between VF and response hand can alter asymmetry (Green, 1977; Green \& Well, Note 1), may bear further consideration, but cannot account for $\mathrm{Ex}$ periment 4 , in which such interactions were found to be nonsignificant at the same time that a RVF advantage was obtained for physical matches.

Experiment 8 deserves special mention. Since much of the author's recent work has supported the superiority of bilateral stimulus presentation over unilateral presentation in producing asymmetry (Boles, 1979), it had been hoped that the procedure adopted in this experiment would clarify the overall results. There are a number of possibilities why this procedure may have failed to produce asymmetry: (1) $\mathrm{Bi}$ lateral presentations may not result in increased asymmetry using a RT measure, since the author's prior efforts have employed accuracy measures; (2) the mechanism underlying the superiority of bilateral presentations may not operate in situations in which the stimuli themselves do not change over conditions, but only in the way they are paired; or (3) the null hypothesis may be the correct one for letter-matching asymmetry.

\section{REFERENCE NOTES}

1. Green, J., \& Well, A. D. Interference between processing demands within a cerebral hemisphere. Paper presented at the meeting of the Psychonomic Society, Washington, D.C., 1977.

2. Bagnara, S., Boles, D., Simion, F., \& Umilta, C. Can an analytic/holistic dichotomy explain hemispheric asymmetries? Paper in preparation, 1980.

\section{REFERENCES}

Boles, D. B. The bilateral effect: Mechanisms for the advantage of bilateral over unilateral stimulus presentation in the production of visual field asymmetry. Doctoral dissertation, University of Oregon, 1979.

Cohen, G. Hemispheric differences in a letter classification task. Perception \& Psychophysics, 1972, 11, 139-142.

Conen, G. Hemispheric differences in serial versus parallel processing. Journal of Experimental Psychology, 1973, 97, 349-356.

Davis, R., \& Schмiт, V. Visual and verbal coding in the interhemispheric transfer of information. Acta Psychologica, 1973, 37, 229-240.

Egeth, H., \& Epste in, J. Differential specialization of the cerebral hemispheres for the perception of sameness and difference. Perception \& Psychophysics, 1972, 12, 218-220.

Gazzaniga, M. S. The bisected brain. New York: AppletonCentury-Crofts, 1970.

Geffen, G., Bradshaw, J. L., \& Nettleton, N. C. Hemispheric asymmetry: Verbal and spatial encoding of visual stimuli. Journal of Experimental Psychology, 1972, 95, 25-31. 
GreEN, J. Interference between stimulus and response processing demands within a cerebral hemisphere (Doctoral dissertation, University of Massachusetts, 1977). Dissertation Abstracts International, 1977, 38, 2906.

Hellige, J. B. Hemispheric processing differences revealed by differential conditioning and reaction time performance. Journal of Experimental Psychology, 1975, 104, 309-326.

Hellige, J. B. Changes in same-different laterality patterns as a function of practice and stimulus quality. Perception \& Psychophysics, 1976, 20, 267-273.

Hellige, J. B., Cox, P. J., \& Litvac, L. Information processing in the cerebral hemispheres: Selective hemispheric activation and capacity limitations. Journal of Experimental Psychology: General, 1979, 108, 251-279.

Ledlow, A., Swanson, J. M., \& Kinsbourne, M. Reaction times and evoked potentials as indicators of hemispheric differences for laterally presented name and physical matches. Journal of Experimental Psychology: Human Perception \& Performance, 1978, 4, 440-454.

Lefton, L. A., \& HABER, R. N. Information extraction from different retinal locations. Journal of Experimental Psychology, $1974,102,975-980$.

LEVY, J. Psychobiological implications of bilateral asymmetry. In S. J. Dimond \& J. G. Beaumont (Eds.), Hemisphere function in the human brain. New York: Wiley, 1974.
McKeever, W. F., \& Huling, M. D. Lateral dominance in tachistoscopic word recognition performance obtained with simultaneous bilateral input. Neuropsychologia, 1971, 9, 15-20.

OLson, M. E. Laterality differences in tachistoscopic word recognition in normal and delayed readers in elementary school. Neuropsychologia, 1973, 11, 343-350.

Segalowicz, S. J., \& Stewart, C. Left and right lateralization for letter matching: Strategy and sex differences. Neuropsychologia, 1979, 17, 521-525.

Simon, F. Bagnara, S., Bisiacchi, P., Roncato, S., \& Umilta, C. Laterality effects, levels of processing, and stimulus properties. Journal of Experimental Psychology: Human Perception and Performance, 1980, 6, 184-195.

Umilta, C., Sava, D., \& Salmaso, D. Hemispheric asymmetries in a letter classification task with different typefaces. Brain and Language, 1980, 9, 171-181.

Wilkins, A., \& Stewart, A. The time course of lateral asymmetries in visual perception of letters. Journal of Experimental Psychology, 1974, 102, 905-908.

(Received for publication November 4, 1980; accepted revision received January 25,1981 .) 